\title{
Comportamento alimentar de vacas Nelore e de seus bezerros puros ou mestiços
}

[Feeding behavior of Nellore cows and their pure or crossbred calves]

\author{
W.B. Rodrigues ${ }^{1,3}$, F.S. Wechsler ${ }^{1}$, D.S. Costa ${ }^{2}$, E. Nogueira ${ }^{3 *}$ \\ ${ }^{1}$ Unesp-Botucatu - Botucatu, SP \\ ${ }^{2}$ Faculdade de Veterinária - UFMS - Campo Grande, MS \\ ${ }^{3}$ Embrapa CPAP - Corumbá, MS
}

\begin{abstract}
RESUMO
O objetivo desta pesquisa foi avaliar a influência do grupo genético do bezerro no comportamento alimentar diurno de mães e suas crias. Foram utilizadas 24 vacas Nelores paridas e seus bezerros, oito Nelores (puros), oito $1 / 2$ Simental $1 / 2$ Nelore e oito 1/2 Red Angus $1 / 2$ Nelore. Avaliaram-se as medidas de frequência e duração das mamadas, tempo de pastejo e ruminação dos bezerros e das vacas. Os bezerros puros mamaram mais frequentemente que os mestiços (3,51 vs. 3,17 vezes/dia), porém com menor duração de mamada (7,37 vs. 7,80 minutos). A frequência de mamadas, a duração de cada mamada e o tempo total de mamadas diminuíram com o aumento da idade do bezerro. Nos bezerros, pastejo e ruminação aumentaram com a idade; entretanto, nas vacas, aumentou o tempo de pastejo e diminuiu o de ruminação com o passar dos dias. Os bezerros mestiços pastaram, em média, 18 minutos a mais que os puros, e os machos 16 minutos a mais que as fêmeas. Os bezerros machos ruminaram, aos 40 dias de idade, 25 minutos a mais que as fêmeas, mas essa diferença diminuiu com a idade e desapareceu por volta dos 220 dias. O comportamento da mãe e de sua cria é influenciado pelo grupo genético desta última.
\end{abstract}

Palavras-chaves: amamentação, cruzamentos, pastejo, ruminação

\begin{abstract}
The aim of this study was to evaluate the effect of a calf's genetic group on the behavior of dam and calf. We used 24 Nellore dams and their calves, of which eight were Nellore, eight were $1 / 2$ Simmental $1 / 2$ Nelore and eight $1 / 2$ Red Angus $1 / 2$ Nellore. Grazing and rumination times, as well as suckling frequency and time, were measured. The straight bred calves suckled more often than the crossbreds (3.51 vs. 3.17 times/day), but their suckling lasted less time (7.37 vs 7.80 minutes). Suckling frequency, suckling length and total time spent suckling decreased as calf age increased. Calf grazing and rumination time increased with age; however, the cows' grazing time increased and rumination time decreased as the days postpartum went by. The crossbred calves grazed, on average, 18 minutes longer than the crossbreds, and the males grazed 16 minutes longer than the females. The male calves grazed, at 40 days of age, 25 minutes longer than the females, but this difference decreased as they grew and disappeared around 220 days. In conclusion, dam and calf behavior are influenced by the calf's genetic group.
\end{abstract}

Keywords: crosses, grazing, suckling, rumination

\section{INTRODUÇÃO}

O cruzamento entre raças é um método de melhoramento genético que pode contribuir para melhorar a eficiência produtiva da pecuária de corte do Brasil (Teixeira et al., 2006). Com o crescente uso de cruzamentos, surgiram discussões sobre as raças mais apropriadas para o Brasil, pois todas elas, apesar de terem suas qualidades, possuem, também, diferentes níveis de adaptação às condições de campo (Silveira et al., 2004). No Brasil, vários trabalhos mostram a

Recebido em 17 de setembro de 2014

Aceito em 3 de dezembro de 2015

*Autor para correspondência (corresponding author)

E-mail: eriklis.nogueira@embrapa.br 
superioridade dos produtos oriundos do cruzamento entre touros de raças taurinas e fêmeas Nelores, mantidos em pasto (Alencar et al., 1995; Vargas Jr. et al., 2003).

Pesquisas demonstram que o leite materno é responsável por uma porção significativa (de 20 a $25 \%$ ) da variação no peso à desmama e no ganho de peso do nascimento à desmama (Espasandin et al., 2001; Marques et al., 2005). Fatores genéticos e ambientais podem afetar o comportamento de amamentação dos bezerros e a produção de leite das vacas (Day et al., 1987), e a raça do bezerro pode influenciar o comportamento de amamentação. Das et al. (2000) observaram que o tempo diário de amamentação foi maior para bezerros zebuínos (11,8 minutos) que para bezerros mestiços $(9,4$ minutos); os bezerros zebuínos apresentaram maior frequência de mamadas por dia que os mestiços (2,8 vs. 2,2, respectivamente).

Altas produções de leite e altos pesos de bezerros têm sido associados a maiores frequências de mamadas (Odde et al., 1985), e o tempo total de amamentação diária decresce com a idade dos bezerros de diferentes grupos genéticos (Das et al., 2000). Alencar et al. (1995) encontraram diferenças entre os bezerros $1 / 2$ Canchim $1 / 2$ Nelore e Canchim: os mestiços mamaram com maior duração em menores frequências diárias. Em experimentos realizados com várias raças europeias e com mestiços de europeias com zebuínas, o número total de mamadas declina com o avanço da idade do bezerro (Espasandin et al. 2001), mas a duração de cada mamada não muda (Day et al., 1987).

Objetivou-se avaliar o comportamento alimentar diurno de vacas da raça Nelore e de seus bezerros pertencentes a três grupos genéticos (Nelore, 1/2 Red Angus 1/2 Nelore e 1/2 Simental 1/2 Nelore), no que tange à frequência e à duração de mamadas, pastejo e ruminação dos bezerros e das vacas.

\section{MATERIAL E MÉTODOS}

$\mathrm{O}$ projeto que deu origem ao trabalho foi protocolado e aprovado pelo CEEA da FMVZUnesp, campus de Botucatu, sob o número 102/2006 - CEEA, está de acordo com os princípios éticos na experimentação animal e foi aprovado pela Câmara de Ética em
Experimentação Animal. $\mathrm{O}$ experimento foi realizado no Município de Nova Andradina, estado do Mato Grosso do Sul, Brasil. Foram sorteadas 24 vacas paridas, cujas gestações eram oriundas de inseminação artificial em tempo fixo, em novembro de 2007 , sendo oito mães de bezerros Nelores, oito mães de bezerros $1 / 2$ Nelore $1 / 2$ Red Angus e oito mães de bezerros $1 / 2$ Nelore $1 / 2$ Simental, tendo cada grupo quatro bezerros e quatro bezerras. A ordem de parto das vacas variou de três a cinco partos. Para cada avaliação, colocaram-se os animais, um dia antes de se iniciar cada período de observação, em um piquete de 5 ha, com boa qualidade de pastagem (Brachiaria brizantha Stapf), mistura mineral, água à vontade e topografia plana. Os animais foram identificados com tinta. As observações foram realizadas sempre em duas etapas: no primeiro dia, coleta de dados dos bezerros; e, no segundo dia, coleta de dados das vacas. As observações relativas às mamadas foram realizadas sete vezes, mensalmente, a partir de dezembro; e as de pastejo e ruminação, quatro vezes, em janeiro, fevereiro, abril e junho. A observação se iniciava ao clarear o dia e terminava quando a luminosidade não permitia mais a visualização. Esses dados foram ajustados para uma duração padrão de 12 horas.

Os resultados foram analisados estatisticamente por meio de máxima verossimilhança restrita, usando-se o programa MIXED do SAS (Littel et al., 1996).

O modelo para análise da frequência e duração da mamada, tempos diurnos de pastejo e ruminação dos bezerros incluiu, como fixos, os efeitos de grupo genético, sexo do bezerro, dias após o parto (medidas repetidas) e interações entre dois fatores; e, como aleatórios, os efeitos de touro dentro do grupo genético, bezerro dentro da combinação de touro e sexo (parcela principal) e resíduos. Presumiu-se uma autocorrelação de primeira ordem entre medidas sucessivas do mesmo animal. $\mathrm{Na}$ análise de tempo de pastejo e ruminação dos bezerros, incluíram-se também os efeitos linear e quadrático de ordem de parto. $\mathrm{O}$ modelo para análise do tempo diurno de pastejo e de ruminação das vacas foi igual ao dos bezerros, exceto pela exclusão do efeito de touro e das covariáveis. Em todos os casos, os efeitos de grupo genético foram desdobrados mediante dois contrastes: Nelores vs. mestiços e $1 / 2$ Nelore $1 / 2$ 
Red Angus vs. $1 / 2$ Nelore $1 / 2$ Simental. Adotou-se como nível de significância $\mathrm{P}<0,05$.

\section{RESULTADOS E DISCUSSÃO}

Os bezerros Nelores apresentaram maior frequência de mamadas e menor duração de cada mamada que os mestiços; todavia, não se observou diferença entre grupos genéticos quanto ao tempo total diário gasto em mamadas (Tab. 1). A frequência de mamadas (Fig. 1) e a duração total de mamadas (Fig. 2) diminuíram $(\mathrm{P}<0,0001)$ com a idade do bezerro. Também se observaram efeitos linear e quadrático de ordem do parto para a frequência e a duração total da mamada.

Tabela 1. Médias ajustadas de frequência, duração e tempo total de mamadas diurnas dos bezerros pertencentes a três grupos genéticos

\begin{tabular}{|c|c|c|c|c|}
\hline Variável & Grupo genético & Média \pm EP & Contraste & $\mathrm{P}$ \\
\hline \multirow{3}{*}{$\begin{array}{c}\text { Frequência de } \\
\text { mamadas } \\
(/ \text { dia })\end{array}$} & Nelore & $3,51 \pm 0,09$ & Nelores vs. mestiços & 0,049 \\
\hline & $1 / 2$ Red Angus $1 / 2$ Nelore & $3,24 \pm 0,13$ & Mestiços entre si & 0,416 \\
\hline & $1 / 2$ Simental $1 / 2$ Nelore & $3,10 \pm 0,07$ & & \\
\hline \multirow{3}{*}{$\begin{array}{c}\text { Duração de } \\
\text { cada mamada } \\
\text { (min) }\end{array}$} & Nelore & $7,39 \pm 0,08$ & Nelores vs. mestiços & 0,018 \\
\hline & $1 / 2$ Red Angus $1 / 2$ Nelore & $7,77 \pm 0,12$ & Mestiços entre si & 0,589 \\
\hline & $1 / 2$ Simental $1 / 2$ Nelore & $7,85 \pm 0,07$ & & \\
\hline \multirow{3}{*}{$\begin{array}{l}\text { Duração total } \\
\text { das mamadas } \\
\text { (min/dia) }\end{array}$} & Nelore & $25,9 \pm 0,57$ & Nelores vs. mestiços & 0,148 \\
\hline & $1 / 2$ Red Angus $1 / 2$ Nelore & $25,0 \pm 0,81$ & Mestiços entre si & 0,395 \\
\hline & $1 / 2$ Simental $1 / 2$ Nelore & $24,1 \pm 0,46$ & & \\
\hline
\end{tabular}

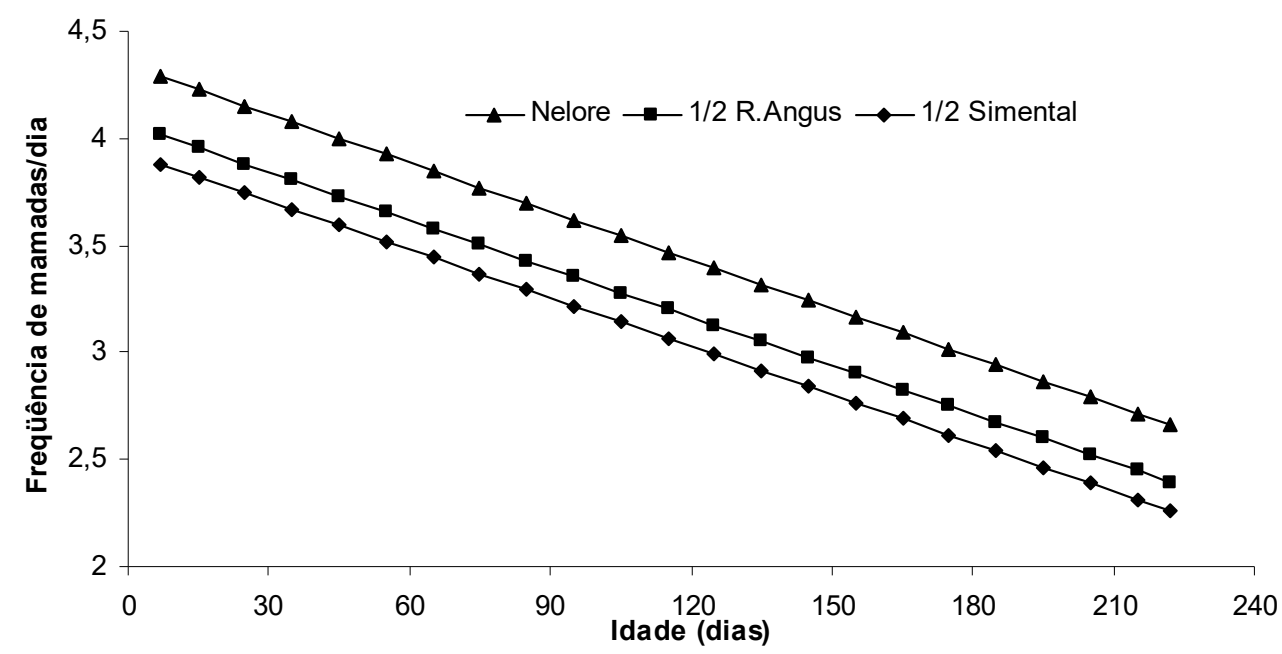

Figura 1. Frequência de mamadas ajustada em função da idade.

Nelore : $\mathrm{Y}=5,0022-0,4617 \mathrm{P}+0,07952 \mathrm{P}^{2}-0,00754 \mathrm{I}$

$1 / 2$ Red Angus $1 / 2$ Nelore: $\mathrm{Y}=4,7339-0,4617 \mathrm{P}+0,07952 \mathrm{P}^{2}-0,00754 \mathrm{I}$;

$1 / 2$ Simental $1 / 2$ Nelore: $\quad \mathrm{Y}=4,5972-0,4617 \mathrm{P}+0,07952 \mathrm{P}^{2}-0,00754 \mathrm{I}$;

em que: $\mathrm{P}=$ ordem de parto; $\mathrm{I}=$ idade (dias). 


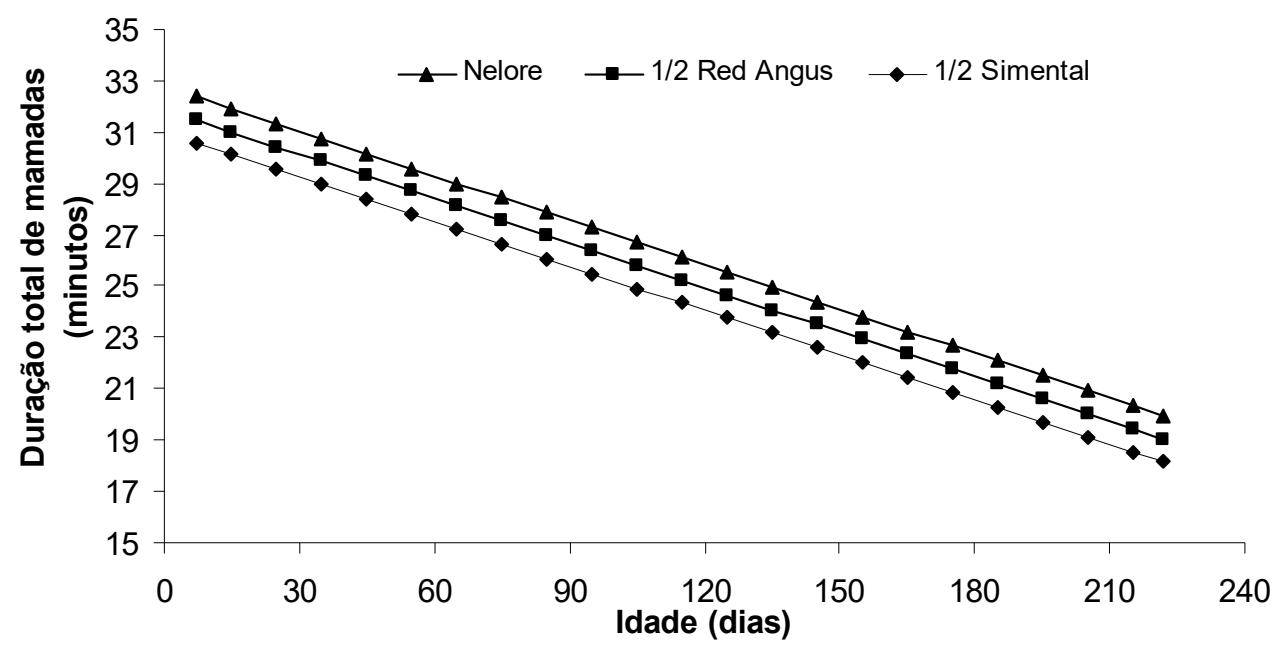

Figura 2. Duração total das mamadas ajustada em função da idade.

Nelore: $\mathrm{Y}=34,3216-1,3818 \mathrm{P}+0,2820 \mathrm{P}^{2}-0,05781 \mathrm{I}$;

$1 / 2$ Red Angus $1 / 2$ Nelore: $\mathrm{Y}=33,4259-1,3818 \mathrm{P}+0,2820 \mathrm{P}^{2}-0,05781 \mathrm{I}$;

$1 / 2$ Simental $1 / 2$ Nelore: $\quad \mathrm{Y}=32,5326-1,3818 \mathrm{P}+0,2820 \mathrm{P}^{2}-0,05781 \mathrm{I}$;

em que: $\mathrm{P}=$ ordem de parto; $\mathrm{I}=$ idade (dias).

Esses resultados podem ser atribuídos à relação materno-filial mais intensa nos zebuínos, que faz com que o bezerro Nelore se torne mais dependente da mãe (Solano et al. 2005, Paranhos da Costa e Costa e Silva, 2007). Os resultados estão de acordo com os de Alencar et al. (1995) e Espasandin et al. (2001), no que se refere ao efeito do grupo genético na duração e frequência de mamadas; já Vargas Jr. (2003) encontrou efeito somente na frequência de mamadas. A diminuição da frequência com a idade corrobora resultados de Alencar et al. (1995), Das et al.
(2000), Espasandin et al. (2001), Vargas Jr. (2003) e Paranhos da Costa et al. (2007).

Sobre o tempo de pastejo dos bezerros, observou-se efeito quadrático de idade $(\mathrm{P}<$ 0,0001). Com o aumento da idade, esse tempo aumentou, estabilizando-se por volta dos sete meses (Fig. 3). Os mestiços gastaram, em média, 18 minutos a mais pastando que os puros $(\mathrm{P}=0,0361)$; e os machos gastaram, em média, 16 minutos a mais que as fêmeas $(\mathrm{P}=0,0066)$.

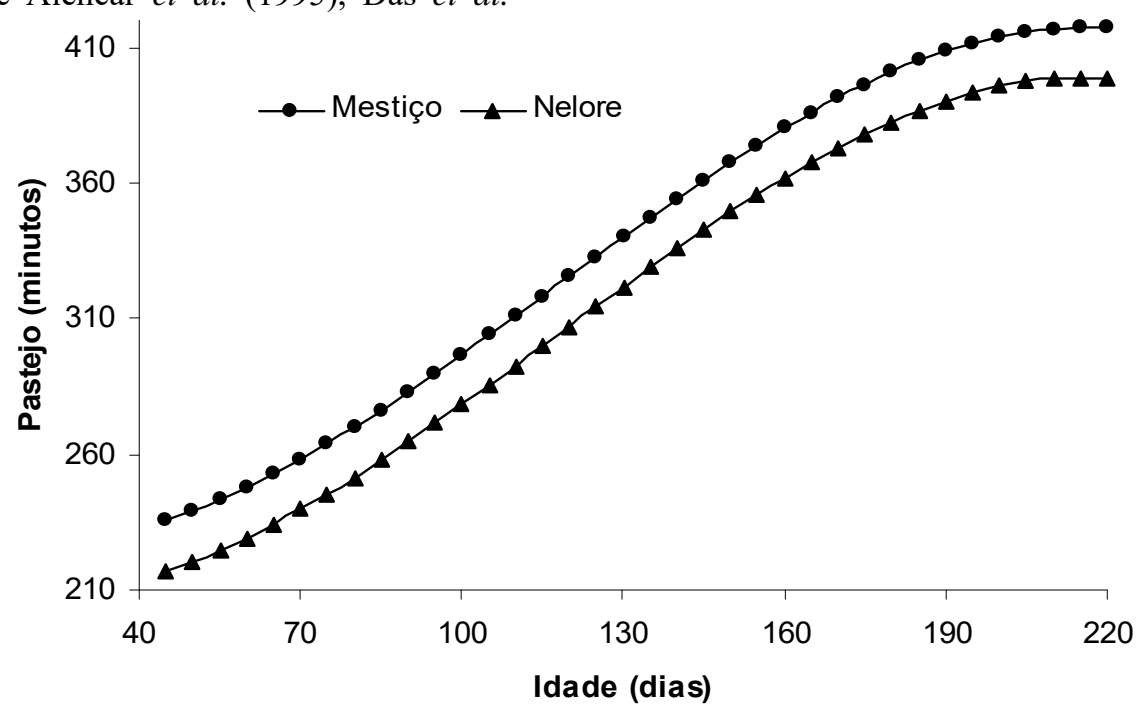

Figura 3. Tempo de pastejo dos bezerros Nelores e mestiços $(1 / 2$ sangue Red $1 / 2$ Nelore e $1 / 2$ sangue Simental $1 / 2$ Nelore), em função da idade. 
Vargas Jr. (2003) também encontrou diferença entre bezerros Nelores e bezerros $1 / 2$ Simental $1 / 2$ Nelore: os bezerros mestiços tiveram um aumento mais rápido no tempo de pastejo. Embora o pico de lactação não seja bem evidente em vacas de corte, Albertini et al. (2007) encontraram o pico de lactação de 7 litros/dia para vacas mestiças $1 / 2$ Caracu $1 / 2$ Nelore e $1 / 2$ Angus $1 / 2$ Nelore, aos 60 dias, quando a mensuração foi feita por meio de mamada controlada (pesa-mama-pesa), e aos 90 dias, com mensuração por ordenha mecânica. Roco (2004), ao comparar os dois métodos de avaliação em vacas Nelores, não encontrou diferenças entre esses métodos para a produção de leite, porém encontrou interação entre dias em lactação e o método utilizado, e observou que a ordenha mecânica teve um declínio mais acentuado.

Em vacas Nelores, o pico tende a ocorrer mais cedo, em torno dos 30 dias, atingindo 4,7 litros, podendo permanecer estável até os 80 dias, quando começa a declinar, chegando rapidamente a 2,5 litros/dia (Marques et al., 2005). Vargas Jr. (2003) encontrou queda de forma quadrática com o avanço da lactação, enquanto Alencar et al. (1995) citam queda contínua linear da produção de leite ao avançar da lactação. Isso faz com que os bezerros diminuam o tempo total de mamadas e haja necessidade da complementação alimentar. Estima-se que, em torno dos 90 dias de idade, os bezerros obtêm $50 \%$ de suas necessidades diárias no leite ingerido e $50 \%$ na pastagem (Nogueira et al., 2006). Bezerros mestiços começam a pastar mais cedo para satisfazer sua demanda nutricional, pois seu mais alto potencial de crescimento faz com que eles exijam maior quantidade de nutrientes; se os nutrientes oriundos do leite não forem suficientes, então eles terão de buscá-los nas pastagens.

Quanto ao efeito de sexo sobre o tempo de pastejo (Fig. 4), observado na presente pesquisa, acredita-se estar associado ao desenvolvimento fisiológico mais lento da fêmea em relação ao macho (Bocchi et al., 2004; Nogueira et al., 2006). Odde et al. (1985) afirmam que altos pesos à desmama estão relacionados com alta produção de leite e maiores quantidades de mamada, fazendo com que o bezerro busque mais cedo o hábito de pastejo.

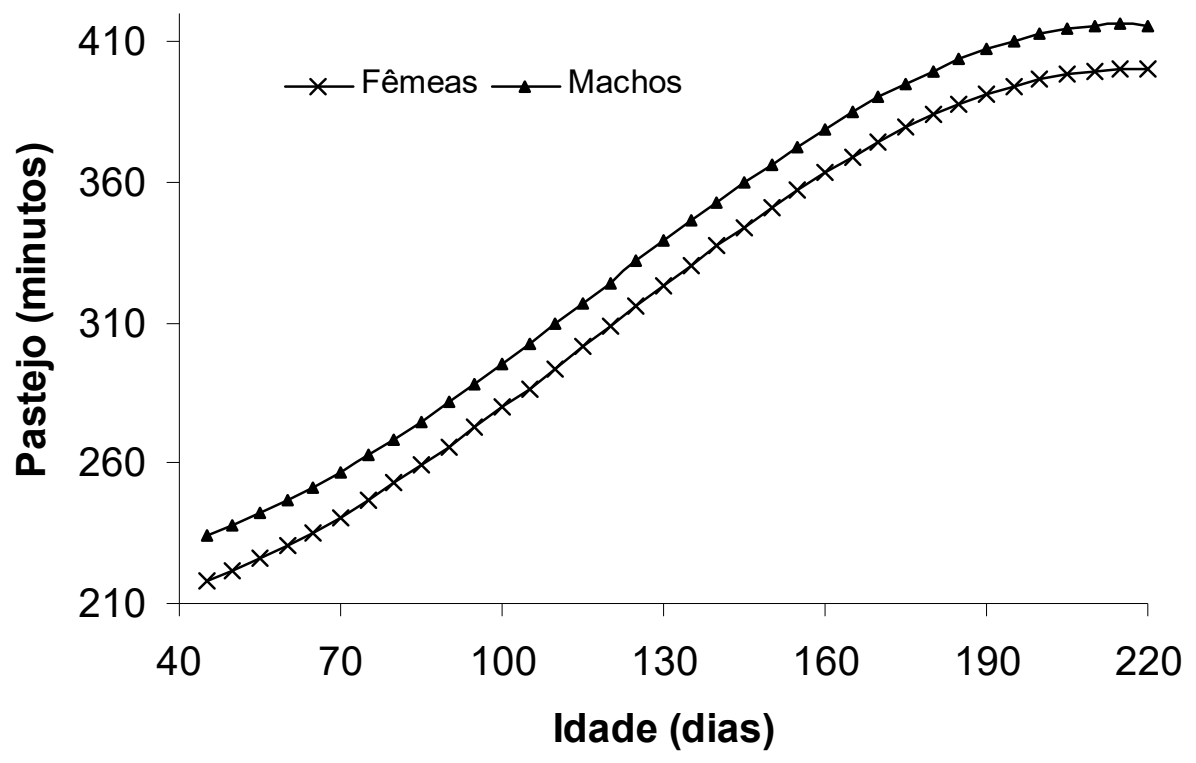

Figura 4. Tempo de pastejo dos bezerros puros Nelores e mestiços, machos e fêmeas, em função da idade.

No tempo de ruminação dos bezerros (Fig. 5), observou-se efeito da idade, efeito quadrático da ordem de parto das mães, do sexo $(\mathrm{P}<0,0001)$ e interação sexo e idade $(\mathrm{P}<0,0001)$, não tendo sido encontrada diferença $(\mathrm{P}=0,1568)$ entre grupos genéticos. Vacas primíparas produzem menos leite que vacas multíparas; estas produzem bezerros mais vigorosos, que iniciam o pastejo mais cedo (Muniz e Queiroz, 1998). Conforme aumenta o consumo de pasto com a idade do bezerro, é esperado que também aumente o tempo de ruminação, em virtude da 
crescente ingestão de fibra. Os efeitos de sexo e interação de sexo com idade podem ser explicados pelo desenvolvimento mais lento das fêmeas; ao aumentar a idade, essa diferença desaparece gradualmente (Fig. 5).

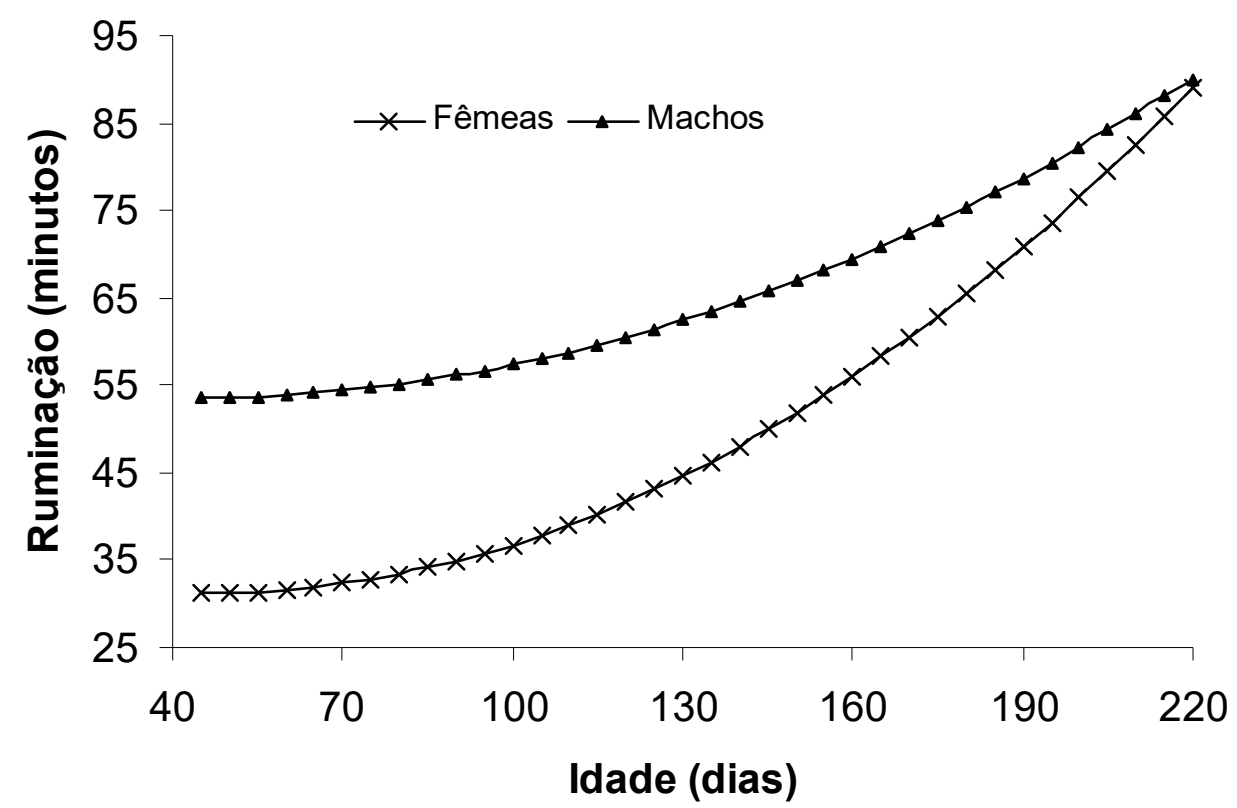

Figura 5. Tempo de ruminação de bezerros puros Nelores e mestiços, de acordo com o sexo, ajustado em função da idade.

O tempo de pastejo das vacas (Fig. 6) não mostrou efeito do grupo genético ou do sexo do bezerro. Somente se observaram efeitos linear, quadrático e cúbico $(\mathrm{P}<0,0038)$ dos dias em lactação, o que pode ser explicado pelo fato de as primeiras observações terem sido feitas durante o verão e as últimas já no outono, quando as vacas presumivelmente gastaram mais tempo à procura de alimento.

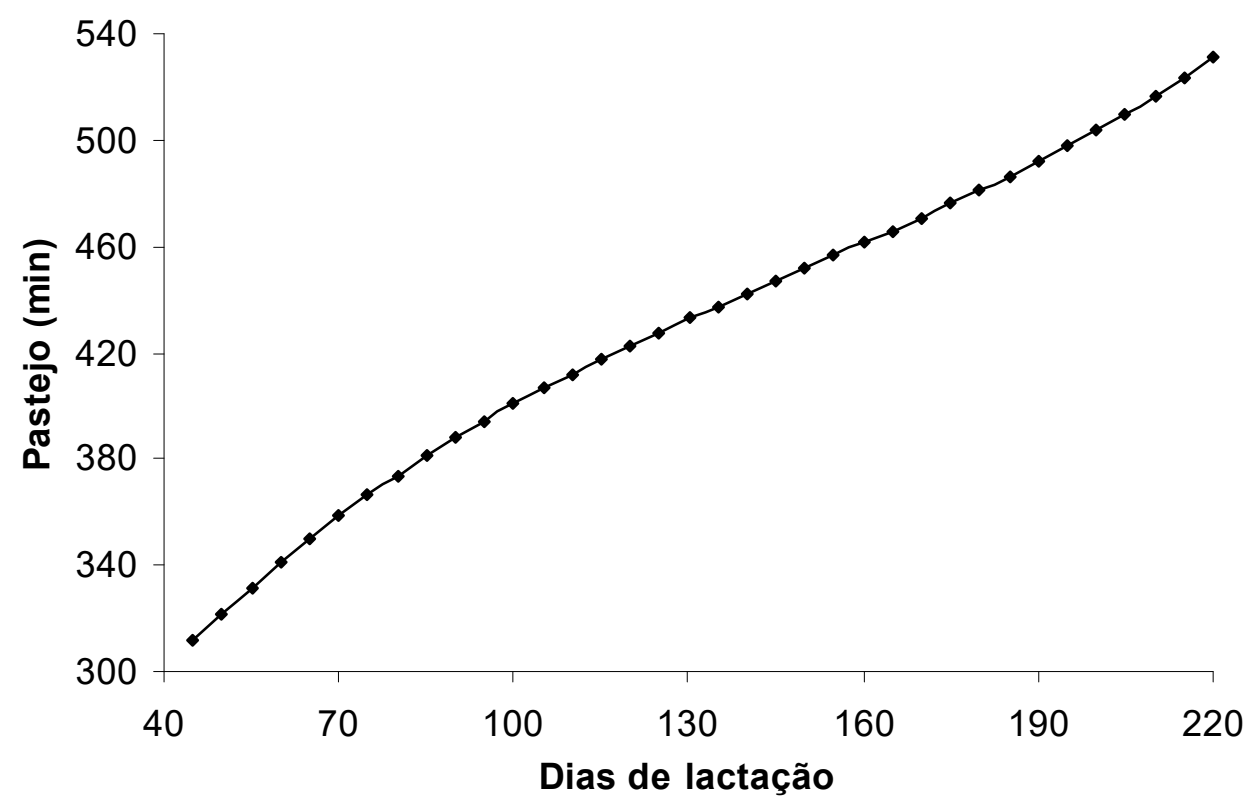

Figura 6. Tempo de pastejo das vacas Nelores, em função dos dias de lactação. 
A média de tempo de pastejo das vacas foi 412 min ou 6,9 horas. Valores considerados normais por Rovira (1996), citado por Vargas Jr. (2003), situam-se entre sete e 10 horas, sendo $70 \%$ desse tempo realizado durante o dia, e os demais $30 \%$ à noite. Com base nessa informação, estimou-se em 9,85 horas o tempo total de pastejo durante 24 horas, valor que está dentro dos padrões considerados normais. Zanine et al. (2007), ao trabalharem com várias categorias, encontraram tempo de pastejo diurno de 5,26, 4,43 e 7,53 horas para novilhas, novilhos e vacas, respectivamente. Santos et al. (2005), ao compararem o pastejo de novilhos em dois tipos de pasto, Brachiaria brizantha e Brachiaria decumbens, encontraram dois tempos diferentes de pastejo, 9,74 e 11,30 horas, respectivamente.

As mães de mestiços apresentaram maior $(\mathrm{P}=0,0295)$ tempo de ruminação, que diminuiu linearmente $(\mathrm{P}<0,0001)$ com o avanço da lactação (Fig. 7).

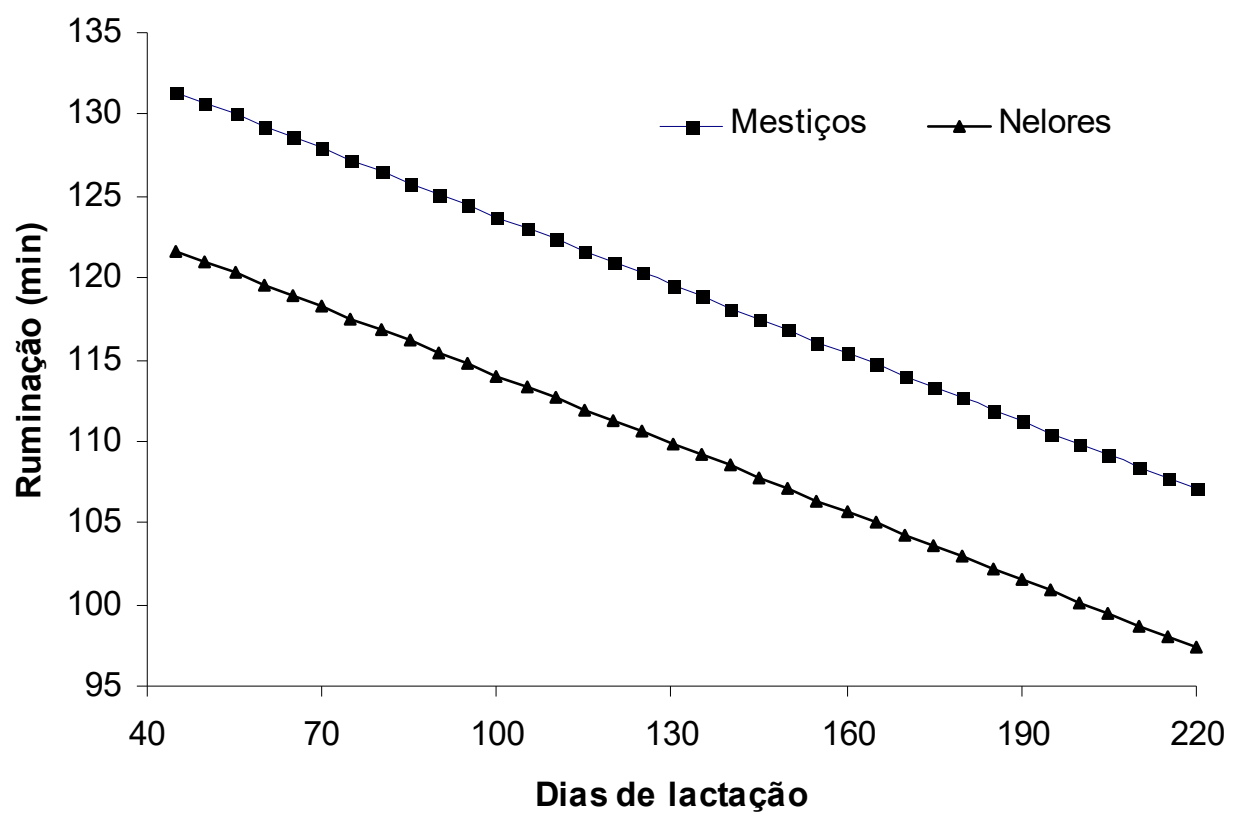

Figura 7. Tempo de ruminação das vacas Nelores mães de bezerros Nelores ou mestiços, em função dos dias de lactação.

Resultados semelhantes foram relatados por Vargas Jr. (2003), que encontrou efeito dos dias de lactação, do grupo genético do bezerro e interação entre grupos genéticos e dias de lactação. A duração da ruminação depende da quantidade de material fibroso ingerido. Mesmo que as vacas aumentem seu tempo de pastejo tentando buscar mais alimentos, a qualidade da pastagem e a disponibilidade de matéria seca tendem a piorar, à medida que se avança em direção ao período seco do ano. Assim, o aumento no tempo de pastejo com os dias de lactação (Fig. 5), presumivelmente, foi acompanhado por uma redução do consumo, que redundou em menor tempo de ruminação (Fig. $6)$.
Vacas amamentam nos períodos de ócio e ruminação. A associação entre amamentação e tempo de pastejo, ruminação e ócio pode ser a explicação para a diferença entre ruminação das mães de mestiços e Nelores. O menor tempo de ruminação das mães de Nelores talvez se deva à maior frequência de mamadas destes (Tab. 1), que pode ter interferido na ruminação materna.

Zanine et al. (2006) afirmam ser muito difícil mensurar separadamente cada variável, pois as medidas comportamentais de pastejo, ruminação e ócio estão diretamente relacionadas ao tamanho e à taxa de bocado, que, por sua vez, estão associados ao dossel forrageiro, à altura deste, à relação colmo:folha e à senescência. 


\section{CONCLUSÕES}

Bezerros da raça Nelore dependem mais da mãe, mamando mais frequentemente, porém com mamadas mais curtas, que bezerros $1 / 2$ Red Angus $1 / 2$ Nelore ou $1 / 2$ Simental $1 / 2$ Nelore. O tempo total da mamada foi semelhante para bezerros puros e mestiços, com esta diferença de comportamento refletindo nas vacas, pois mães de bezerros puros despendem menos tempo ruminando. Bezerros mestiços pastaram mais tempo que os Nelores até à desmama. Bezerros machos ruminaram mais longamente que as fêmeas na fase inicial do período de amamentação, mas não há evidência de efeito do grupo genético nesta variável.

\section{REFERÊNCIAS}

ALBERTINI, T.Z.; MEDEIROS, S.R.; TORRES JR., R.A.A; LANNA, D.P.D. Características das curvas de lactação de vacas de corte cruzadas obtidas por diferentes métodos. In: REUNIÃO ANUAL DA SOCIEDADE BRASILEIRA DE ZOOTECNIA, 44., 2007, Jaboticabal, SP. Anais... Sociedade Brasileira de Zootecnia, 2007.

ALENCAR, M.M.; CRUZ, G.M.; TULIO, R.R.; CORRÊA, L.A. Características da amamentação de bezerros da raça Canchim e cruzados Canchim x Nelore. Rev. Bras. Zootec, v.24, p.706-714, 1995.

BOCCHI, A.L.; TEIXEIRA, R.A.; ALBUQUERQUE, L.G. Idade da vaca e mês de nascimento sobre o peso ao desmame de bezerros nelore nas diferentes regiões brasileiras. Acta Sci. Anim. Sci., v.26, p.475-482, 2004.

DAS, S.M.; REDBO, I.; WIKTORSSON, H. Efect of age of calf on suckling behavior and other behavior activities of zebu and crossbred calves during restricted suckling periods. Appl. Anim. Behav. Sci., v.67, p.47-57, 2000.

DAY, M.L.; IMAKAWA, K.; CLUTTER, A.C. Suckling behavior of calves with dams varying in milk production. J. Anim. Sci., v.65, p.1207$1212,1987$.

ESPASANDIN, A.C.; PACKER, I.V.; ALENCAR, M.M. Produção de leite e comportamento da amamentação em cinco sistemas de produção de gado de corte. Rev. Bras. Zootec., v.30, p.702-708, 2001.
LITTELL, R.C.; MILLIKEN, G.A.; STROUP, W.W. et al. SAS ${ }^{\circledR}$ system for mixed models. Cary, NC: SAS Institute Inc., 1996. 633p.

MARQUES, J.A.; ZAWADZKI, F.; CALDAS NETO, S.F.; CROFF, A.M.; PRADO, I.I.; SILVA, R.E. Efeitos da suplementação alimentar de bezerros mestiços sobre o peso a desmama e taxa de prenhez da vacas multíparas Nelore. Arch. Latinoam. Prod. Anim., v.13, p.92-96, 2005.

MUNIZ, C.A.S.D.; QUEIROZ, S.A. Avaliação do peso à desmama e do ganho médio de peso de bezerros cruzados, no estado de Mato Grosso do Sul. Rev. Bras. Zootec., v.27, p.504-512, 1998.

NOGUEIRA, E.; MORAIS, M.G.; ANDRADE, V.J. et al. Efeito do creep-feeding sobre o desempenho de bezerros e a eficiência reprodutiva de primíparas Nelore em pastejo. Arq. Bras. Med. Vet. Zootec., v.58, p.607-813, 2006.

ODDE, K.G.; KIRACOFE, G.H.; SCHALLES, R.R. Suckling behavior in range beef calves. J. Anim. Sci., v.61, p.631-642, 1985.

PARANHOS DA COSTA, M.J.R.; COSTA E SILVA, E.V. Aspectos básicos do comportamento social bovino. Rev. Bras. Reprod. Anim., v.31, p.172-176, 2007.

PARANHOS DA COSTA, M.J.R.; SCHIMIDEK, A.; TOLEDO, L.M.; Relações materno-filiais em bovinos de corte do nascimento à desmama. Rev. Bras. Reprod. Anim., v.31, p.183-189, 2007.

ROCO, V.V.B. Metodologias para avaliar a produção de leite em vacas nelore. 2004. 38f. Dissertação (Mestrado) - Faculdade de Medicina Veterinária e Zootecnia, Universidade Estadual Paulista, Botucatu, SP.

SANTOS, S.A.; SILVA, R.A.M.S.; COMASTRI FILHO, J.A.; et al. Performance of pantaneiro, Nellore and crossbred calves reared in pantanal Brazil. Arch. Zootec., v.54, p.501-508. 2005.

SILVEIRA, J.C.; MCMANUS, C.; MASCIOLI, A.S. et al. Fatores ambientais e parâmetros genéticos para características produtivas e reprodutivas em rebanho Nelore no Estado do Mato Grosso do Sul. Rev. Bras. Zootec., v.33, p.1432-1444, 2004. 
SOLANO, J. ORIHUELA, A. GALINA, C.S. et al. Relationships between social behaviour and mouting activity of zebu cattle (Bos indicus). Appl. Anim. Behav. Sci., v.94, p.197-203, 2005.

TEIXEIRA, R.A.; ALBUQUERQUE, L.G.; ALENCAR, M.M.; DIAS, L.T. Interação genótipo ambiente em cruzamentos de bovinos de corte. Rev. Bras. Zootec, v.35, p.1677-1683, 2006.

VARGAS JR. F.M. Efeito do grupo genético da progênie sobre a eficiência produtiva e reprodutiva de matrizes Nelore. 2003. 96f. Tese (Doutorado) - Faculdade de Medicina Veterinária e Zootecnia, Universidade Estadual Paulista, Botucatu, SP.
VARGAS JR. F.M.; WECHSLER, F.S.; ROSSI, P. et al. Ganho de peso e consumo de leite de bezerros Nelore e $1 / 2$ simental $1 / 2$ nelore. In: REUNIÃO ANUAL DA SOCIEDADE BRASILEIRA DE ZOOTECNIA, 40., 2003, Santa Maria, RS. Anais... Santa Maria, RS: SBZ, 2003.

ZANINE, A.M.; SANTOS, E.M.; FERREIRA, D.J. Tempo de pastejo, ócio, ruminação e taxa de bocados de bovinos em pastagens de diferentes estruturas morfológicas. Rev. Eletr. Vet. REDVET, v.7, 2006.

ZANINE, A.M.; VIEIRA, B.R.; FERREIRA, D.J. et al. Ingestive behaviour of cattle of several categories on coastcross grass pasture. Biosci. J., v.23, p.111-119, 2007. 